\title{
Colonoscopic Review and Surgical Approach in the Management of Colorectal Carcinoma-A Retrospective Study of 50 cases
}

\author{
Ershad-ul-Quadir $M^{1}$, Rahman $M M^{2}$, Rahman $M^{3}$
}

\begin{abstract}
Introduction: There is no exact statistics about the incidence of colorectal cancer in Bangladesh. According to National Cancer Institute, London, it is the 2nd most common cancer affecting more than 30,000 people in each year. As many patients with colon cancer do not develop symptoms until it is advanced and detection in early stage can only be achieved by screening of asymptomatic person. Maximum patients present lately with distance metastases when there is nothing to treat except palliative therapy.
\end{abstract}

Objectives: To identify the risk factors, early symptoms, signs, treatment modalities, operative outcome, morbidity and mortality rate.

Materials and Methods: This retrospective study was carried out at CMH Dhaka during August 2002 to August 2004. A total of 50 patients were taken as study sample. All the patients were admitted in different surgical units of $\mathrm{CMH}$ Dhaka for surgical treatment. Detailed history were taken on admission by a questionnaire and examined thoroughly and findings regarding Anaemia, Jaundice, Dehydration, Oedema, Lymphadenopathy, Nutritional status and abnormal signs like ascites, distension, rigidity, organomegaly recorded. Digital rectal examination were done in all cases and finally examined by Proctoscope, Sigmoidoscope and with Colonoscope. FOBT (Fecal Occult Blood Test), serum tumour marker was also assessed.

Results: Out of 50 cases 22 were rectal carcinoma and next common site was caecum and number was 10. There was a variation in the sex ratio. Out of 50 cases 33 were male and 17 were female. The highest incidence was among people of 6th decade $(28 \%)$ and next highest was in 4th decade (24\%). Majority of patient with right colon cancer presented with abdominal pain 12 out of 22 cases $(56 \%)$ and weight loss 15 cases (68\%). For left colon cancer commonest symptom was weight loss and weakness and altered bowel habit. Almost all cases with rectal carcinoma presented with bleeding per rectum.

Conclusion: About $50 \%$ of lesions were found in recto-sigmoid junction and male: female ratio was 1.9:1. All efforts and modern technology should be applied for early detection and treatment. The survival rate is usually very poor in rectal carcinoma. In this study most of the cases were subjected to post operative Chemo and Radiotherapy, but more were treated with neoadjuvant chemoradiation for down staging. The need for early detection of Colorectal Carcinoma (CRC) should be stressed in the form of screening patient awareness and understanding about symptomatology. Early diagnosis and definitive treatment are thereby increasing expectation of higher survival and better prognosis in patient of colorectal carcinoma.

Key-words: Colorectal Carcinoma, Palliative Therapy, Serum Tumour Marker, Fecal Occult Blood Test (FOBT), Carcino Embryonic Antigen (CEA).

\section{Introduction}

There is no exact statistics about the incidence of colonic cancer in Bangladesh. According to National cancer Institute, London April 2001, it is the 2nd most common cancer affecting more than 30,000 people in each year. $80 \%$ of these cases are not diagnosed until the cancer has spread the bowel or beyond. Such cases have worse prognosis than carcinoma confined to bowel wall. As many patients with colon cancer do not develops symptoms until the carcinoma is advanced. The early detection of greater portion can only be achieved by the screening of asymptomatic persons.

1. Lt Col Md Ershad-ul-Quadir, MBBS, FCPS, Classified Surgical Specialist, BNS Patenga, Navy Hospital 2. Maj Gen Munshi Md Mojibur Rahman, MBBS, MCPS, FICS, FCPS(Surgery), Consultant Surgeon General, Bangladesh Armed Forces, Ministry of Defence, Director General of Medical Services 3. Brig Gen Md Mahbubur Rahman, MBBS, FCPS (Surgery), Fellow Colorectal Surgery, Chief Surgeon, CMH, Dhaka. 
Maximum patient present lately with distance metastases when there is nothing left to surgeon to treat these unfortunate cancer victims excep palliative therapy.

Screening and detection of the early presentation of carcinoma are the two important tools, used to reduce the cancer related morbidity and this study choiced the later one and selected those patients who are already diagnosed as Ca-colon to find out any clue related to earlier presentation. This study with limitation tried to identify the risk factors, early symptoms, signs, treatment modalities, operative outcome, morbidity, mortality rate and also tried to find out the suitable-investigations for these patients. This study is a tip of ice-burg of a vast subject and it recommends further study to draw a complete conclusion

\section{Materials and Methods}

This retrospective study of 50 cases of colorectal carcinoma carried out in different surgical units at $\mathrm{CMH}$ Dhaka during the period from August 2002 to August 2004. For all cases, detailed history of the patients on admission was taken by a questionnaire. The cases were examined thoroughly and genera findings regarding Anaemia, Jaundice, Dehydration Oedema, Lymphadenopathy, Nutritional status and abnormal signs- like ascites, distension, rigidity, organomegaly were recorded. Digital recta examinations were done in a examinations were done in all cases. Patients scope and finally with colonoscope. Fecal Occult Blood Test (FOBT) and serum tumour marker were also assessed.

Relevant routine investigations were done in all contrast barium enema of large gut was done for all cases except those with intestinal obstruction, perforation, also refusal for painful condition and inability to hold-up the solution. IVU were also done in selected cases. Pre-operative biopsy and histopathology were done to confirm the clinical findings. Some sorts of operations were under taken ranging from biopsy to radical excision. Pre-operative findings were recorded and total abdominal exploration was made. Tissues were taken from the lesions and the lymph nodes were taken where feasible.
Histopathological examinations were done for each case. Post operative period were followed up to note any morbidity and mortality. Patients were advised to follow up for further chemotherapy and radiotherapy one month after operation or earlier in case where there are any complications.

\section{Results}

In this study the statistical data were collected from the detailed information of each case which have been presented in tabulated form.

Table-I: Sex and site involved $(n=50)$

\begin{tabular}{|c|c|c|c|c|c|}
\hline Sites & Cases & $\begin{array}{c}\text { Cases } \\
(\mathrm{n}=50)\end{array}$ & Male & Female & $\begin{array}{l}\text { M: F } \\
\text { Ratio }\end{array}$ \\
\hline Caecum & $10(20 \%)$ & \multirow{3}{*}{$22(44 \%)$} & 8 & 2 & 3:4:1 \\
\hline Ascending colon & $8(16 \%)$ & & 7 & 1 & \\
\hline Right colic flexure & $4(8 \%)$ & & 2 & 2 & \\
\hline Transverse colon & 0 & \multirow{4}{*}{$6(12 \%)$} & & & \\
\hline Left colic flexure & $1(2 \%)$ & & 1 & & $2: 1$ \\
\hline Descending colon & $2(4 \%)$ & & & 1 & \\
\hline Sigmoid colon & $3(6 \%)$ & & 2 & 1 & \\
\hline Rectosigmoid junction & 0 & & & & \\
\hline Rectum & $22(44 \%)$ & $22(44 \%)$ & 12 & 10 & 1:2:1 \\
\hline Total & 50 & & 33 & & 1:9:1 \\
\hline
\end{tabular}

Table-I shows involvement of colorectal carcinoma in different sites and sexes. Out of 50 cases 22 were rectal carcinoma. The next common site was caecum and the number was 10 . The relative incidence in the study was approximately $44 \%$ for rectum, $44 \%$ for Right colon and $12 \%$ for Left colon. Out of 50 cases 33 were male and 17 were female. In all sites males are affected more than females.

Table-II: Incidence in different age groups $(n=50)$

Table-II: Incidence in different age groups $(\mathrm{n}=50)$
\begin{tabular}{|l|c|c|c|c|}
\hline Age (Years) & Total (no) & th side & Lt side & Rectum \\
\hline $10-20$ & $3(6 \%)$ & $1(2 \%)$ & $1(2 \%)$ & $1(2 \%)$ \\
\hline $21-30$ & $9(18 \%)$ & $5(10 \%)$ & 0 & $4(8 \%)$ \\
\hline $31-40$ & $12(24 \%)$ & $5(10 \%)$ & $4(8 \%)$ & $3(6 \%)$ \\
\hline $41-50$ & $10(20 \%)$ & $6(12 \%)$ & 0 & $4(8 \%)$ \\
\hline $51-60$ & $14(28 \%)$ & $3(6 \%)$ & $1(2 \%)$ & $10(20 \%)$ \\
\hline $61-70$ & $1(2 \%)$ & $1(2 \%)$ & 0 & 0 \\
\hline $71-80$ & $1(2 \%)$ & $1(2 \%)$ & 0 & 0 \\
\hline $81-100$ & 0 & 0 & 0 & 0 \\
\hline Total & $\mathbf{5 0}$ & $\mathbf{3 ( 6 \% )}$ & $\mathbf{6 ( 1 2 \% )}$ & $\mathbf{2 2 ( 4 4 \% )}$ \\
\hline
\end{tabular}

Table-II shows the incidence in different age groups. The highest incidence was found in the age group of 51-60 years age and it was 14(28\%) and next was in $31-40$ years of age and was 12(24\%). One case was detected as early as 14 years and $9(18 \%)$ cases within 21-30 years. Incidence among people within $60-100$ years was relatively less, only $02(4 \%)$ cases and they were carcinoma of right colon. 
Table-III: Distribution of faecal occult blood test

\begin{tabular}{|l|c|c|}
\hline Site & Positive & Negative \\
\hline Right colon & 15 & 7 \\
\hline Left colon & 5 & 1 \\
\hline
\end{tabular}

Table-III shows the result of faecal occult blood test of Ca-colon. Fifteen (66\%) cases were found positive for right colonic carcinoma and $5(82 \%)$ patients were for left colon. But 7 (34\%) cases and 1 $(17 \%)$ case showed negative result in right and left colonic carcinoma respectively.

Table-IV: Result of Flexible Colonoscopy

\begin{tabular}{|l|c|c|c|}
\hline Site & Positive & Negative & Not Done \\
\hline Right colon & 17 & 4 & 1 \\
\hline Left colon & 6 & 0 & 0 \\
\hline
\end{tabular}

Table-IV shows the colonoscopic report on carcinoma colon. In case of right colon 17 (82\%) cases found positive result and $4(18 \%)$ cases are negative result. This test was not possible in $1(4.5 \%)$ cases. On the other hand it was surprisingly enough that almost $100 \%$ positive in case of left colon.

Table-V: Result of serum marker - CEA $(n=50)$

\begin{tabular}{|l|l|l|}
\hline Normal & Raised upto $\mathbf{5 0 ~ n g / m l ~}$ & Raised $>\mathbf{5 0} \mathbf{~ n g} / \mathbf{m l}$ \\
\hline $23(46 \%)$ & $15(30 \%)$ & $12(24 \%)$ \\
\hline
\end{tabular}

Table-V shows the result of serum marker - CEA. Out of 50 cases $23(46 \%)$ cases normal value, 15 $(30 \%)$ cases raised upto $50 \mathrm{ng} / \mathrm{ml}$ and $12(24 \%)$ cases raised more than $50 \mathrm{ng} / \mathrm{ml}$.

Table-VI: Result of Barium enema X-Rays $(n=50)$

\begin{tabular}{|l|l|l|l|}
\hline Result & Right colon & Left colon & Rectum \\
\hline Positive & $18(82 \%)$ & $6(100 \%)$ & $5(23 \%)$ \\
\hline Negative & $3(14 \%)$ & 0 & $15(69 \%)$ \\
\hline Not done & $1(5 \%)$ & 0 & $2(10 \%)$ \\
\hline
\end{tabular}

Table-VI shows the result of Ba-enema X-rays done for carcinoma in most of cases. $100 \%$ of the left colonic cancer revealed positive impressions in the Ba-enema X-ray of the large gut but in rectal cancer negative in majority of cases is $15(69 \%)$ and positive in only $5(23 \%)$ cases. Examination was not done in $3(15 \%)$ cases due to refusal for painful condition and inability to hold up the solution.
Table-VII: Operation due to lesions at different sites ( $\mathrm{n}=50)$

\begin{tabular}{|l|c|c|c|c|}
\hline Operations & Rt colon & Lt colon & Rectum & Total \\
\hline Curative resection & $12(24) \%$ & $4(8 \%)$ & $16(32 \%)$ & $32(64 \%)$ \\
\hline Palliative resection & $8(16 \%)$ & $2(4 \%)$ & $4(8 \%)$ & $14(28 \%)$ \\
\hline Palliative bypass & $2(4 \%)$ & $0(0 \%)$ & $0(0 \%)$ & $2(4 \%)$ \\
\hline De-functioning colostomy & 0 & 0 & $2(4)$ & $2(4 \%)$ \\
\hline Only biopsy & 0 & 0 & 0 & 0 \\
\hline & $22(44 \%)$ & $6(12 \%)$ & $22(44 \%)$ & $50(100 \%)$ \\
\hline
\end{tabular}

Table-VII shows in $64 \%$ patients curative resection could be done, of them $16(32 \%)$ were rectal carcinoma, $12(24 \%)$ of right colon, $4(8 \%)$ carcinoma in left colon cancer. The patient with rectal cancer either underwent abdomino-perineal resection (APR) or the anterior resection (AR) as curative resection. Palliative resection had been done in 14 cases; palliative bypass was done in 02 cases of rectal carcinoma. De-functioning colostomy was done in 02 cases of rectal carcinoma.

Table-VIII: Operative morbidity and mortality for colorectal carcinoma

\begin{tabular}{|l|c|c|}
\hline Site & Morbidity & Mortality \\
\hline Right colon & 5 & 2 \\
\hline Left colon & 1 & 0 \\
\hline rectal growth & 4 & 2 \\
\hline Total & 10 & 4 \\
\hline
\end{tabular}

Table-VIII shows the morbidity and mortality following operations for colorectal carcinoma. This study showed maximum mortality and morbidity in right colonic growth. Total mortality was $4(8 \%)$ of which 2 in rectal and 2 in right colon carcinoma. Total morbidity was $10(20 \%)$ of which $5(10 \%)$ in right colon, $4(8 \%)$ in rectum and $1(2 \%)$ in left colon.

Table-IX: Histopathological structure in colorectal carcinoma $(n=50)$

\begin{tabular}{|l|c|c|c|}
\hline Site & Adenocarcinoma & Sq. cell carcinoma & Lymphosarcoma \\
\hline Right colon & $19(38 \%)$ & $0 \%$ & $3(6 \%)$ \\
\hline Left colon & $5(10 \%)$ & $0 \%$ & $1(2 \%)$ \\
\hline Rectum & $22(44 \%)$ & $0 \%$ & $0(0 \%)$ \\
\hline Total & $46(92 \%)$ & $0 \%$ & $4(8 \%)$ \\
\hline
\end{tabular}

Table-IX shows that most of the colorectal carcinoma was adenocarcinoma which represented $92 \%$ of cases, out of which $38 \%$ occurred in right colon, $44 \%$ occurred in rectum and $10 \%$ occurred in left colon carcinoma. But the percentage of lymphosarcoma was also quite high (8\%). 


\section{Discussion}

All the cases were finally diagnosed after being confirmed by histopathological examination. As it is a very small study, it is not possible to draw a conclusion on the overall disease picture. It needs a wider study over a large period including other related diagnoses and long term follow up of each case. Carcinoma of the colon and rectum occur with different frequencies in various segments. Most of the colorectal carcinoma occurs in the distal colon and rectum, $38 \%$ within the reach of examining finger and $60 \%$ within the reach of sigmoidoscope. Virtually $98 \%$ of all cancers of large bowel are

The exact aetiology is not known, but there are certain predisposing conditions. e.g. familial polyposis, Gardner's syndrome, villous tumours, ulcerative colitis and previous history of colorectal carcinoma. There is little evidence that adenomatous polyp contribute significantly. Genetic factors have been suggested but without any convincing evidence.

Grossly, colorectal carcinomas are described as polypoid mass projecting into the lumen, like cauliflower, nodular, ulcerating and schirrous or stenotic. The tumours have been classified descriptively in number of way, but distinguish into two patterns carcinoma of the left side and carcinoma of the right side.

Unlike the gross pathology, the microscopic appearances of the right and left sided carcinoma are similar. $95 \%$ of all carcinoma of the colon are well differentiated adenocarcinoma, secreting variable amount of mucin, occasionally undifferentiated growth is observed. They are variant called linitis plastica. Colorectal carcinoma spread by direct extension, lymphatics or blood stream dissemination, by gravitational seeding and by implantation at operation. The growth may invade the paracolic tissue and mesocolon. Outside the bowel wall, the main line of spread is lymphatic channels. Regional lymph node involvement is most common form of metastasis in colorectal carcinoma. Recurrences after operation for carcinoma of colorectum are frequently at or near the anastomosis. Even though the operation was considered to be histologically free from tumour.
In this study, maximum incidence was found in the people of age group 51-60 years (28\%) follwed by $31-40$ years, $41-50$ years and $21-30$ years (18\%) respectively. In the age group 51-60 years again the highest percentage was the rectum. Incidences of colorectal carcinoma in the $31-40$ and $21-30$ years were significantly higher than in the 61-70 and 71-80 years of age group. Two cases of advanced rectal carcinoma were found in the 10-20 years of group.

In this study the overall male, female ratio was 1.9:1 and majority of colorectal carcinoma occurs in rectal area $(44 \%)$ followed by right colon $(44 \%)$ and left colon $(12 \%)$. This study reveals majority $(50 \%)$ of the lesion occurs in rectum and majorities are male.

Majority of lesion in right colon presented with abdominal pain, anaemia, weight loss with general weakness and abdominal lump, but bleeding per rectum, altered bowel habits were commonly associated with lesions in rectum and left colon. Bleeding per rectum was a highly significant presenting feature for lesion in rectum. Twenty out of 22 cases $(91 \%)$ presented with this symptom. Altered bowel habit was also an association with lesion of the left colon (83\%) and rectum (50\%).

The post operative complications were not so high and almost all were managed by conservative approaches. The surgical mortality rate was comparatively low ( $8 \%$ ) of which 2 cases were following radical abdomino-perineal resection, 2 after palliative resections followed by radiotherapy. The overall survival in this study could not be assessed properly, due mainly to the proper follow up. Four out of 50 cases succumbed to complication and death in the early post operative period.

\section{Conclusion}

Skillness in further improvement in the field of early diagnosis and treatment depend on advance knowledge of biological behavior and technique of diagnosis of colorectal carcinoma. It has to be carried out involving more treatment centre and acquire better information about whole disease process and management in our country. Since the early diagnosis in any form of malignancy specially a colorectal carcinoma has definitely better prognosis and improved cure rate. So the need for early detection of colorectal carcinoma should be stressed 
in the form of screening and patient's awareness and understanding about symptomatology. Early diagnosis and definitive treatment thereby increasing expectation of higher survival rate and better prognosis in patient of colorectal carcinoma.

\section{References}

1. William PL, Warwick R. Dyson M, et al. Gray's anatomy. 38th Ed. 1996; 772, 818, 853-1365, 1365-75. London: ELBS with Churchill Livingstone.

2. Salder TW. Langman's Medical Embryology. 8th ed. Williams and Wilkinsons 2000; 248-57.

3. Guyton AC. Textbook of medical physiology, 10th ed. Philadelphia, W8 Sauderscompsny 1998; 688-94,704-7, 724,734-35.

4. Cotran RS, Kumar V. Robbins pathologic basic of disease, 6 th ed. Philadelphia, WB Sauders company 2000; 815-6.

5. Russell RCG, Williams NS, Bulstode CJK. Bailey and love's short practice of surgery, 24th ed. London Arnold with Oxford University press Inc 2004; 1174-84, 1231-41.

6. Way LW, Doherty GM. Current Surgical Diagnosis and Treatment 11th ed. Lange with McGraw Hill 2001; 715-24.

7. Mc Farlane JF, Ryall RDH, Heald RJ. Mesorectal excision for rectal cancer. Lancet 1993; 341:457-60.

8. Mess MA, Adson MA, Elveback LR, et al. Rectal cancer following colorectomy for polyposis, Arch sury 1980; 460-7.

9. Wanebo HJ. Are carcinoembryonic antigen levels of value in the curative management of colorectal cancer? Surgery 1981 Mar; 89(3):290-5.

10. Mackay M, Ratel S, Caeten S, et al. Role of arterial plasma CEA assay in the detection of recurrent and metastatic colorectal carcinoma. Br Med j 1974; 4:382-5.

11. Wherry DC. Screening for colorectal carcinoma in asymptomatic patient using flexible fiberoptic sigmoidoscopy. Dis colon rectam 1981; 24:521-2.

12. Cuschieri A, Steele RJC, Moossa AR. Essential surgical practice. 4th ed. London, Arnold, Hodder Headling group 2002; 585-97.
13. Aelson MA, VAn Heerden JA. Major hepatic dissection for metastetic colorectal carcinoma. Ann surg 1979; 291: 576-83.

14. Floyd CE, Stirling CT, Cohn IJr. Cancer of the colon, rectum and anus, review of the 1687 cases. Ann surg; 1996; 163:829-37.

15. Salvati EP, Rubin RJ. Electrocoagulation as primary therapy for rectal carcinoma. Am Jsurg 1976; 132:583-6.

16. Crile G JR, Turnbull RB Jr. The role of electeocogulation in the treatment carcinoma of the rectum. SurgGynecol obset 1972; 135:397-6.

17. Lochart mummery HE. Discussion on the management of accurate large bowel obstruction due to carcinoma. Proc R Soc med 1951; 44:785.

18. Cohen AM, Gunderson LL, Welch CE. Selective use of adjuvant radiation therapy in resectable-colorectal carcinoma. Dis colon rectum $1981 ; 24: 247-51$.

19. Chang WYM, burnett WE. Complete colonic obstruction due to adenocarcinoma. Surg Gynecol obstet 1992 March; 353-6.

20. Neal DE, Williams NS, Johnston D. A prospective study of bladder function before and after sphincter saving resection for low carcinoma of the rectum. BrJSurg 1981; $53: 558-9$

21. Tytherleigh MG, MacMortensen NJ. Options for sphincter perseveration in surgery for low rectal cancer. British Journal of Surgery 2003; 90:922-33.

22. Irvin TT, Greaney MG. The treatment of colonic cancer presenting with intestinal obstruction. Br Jsurg 1977; 64 (10):741-4

23. Islam AKMS. Tumours of large bowel, a clinical review. (dissertation) Dhaka: BCPS1985.

24. Rashid MH. Tumours of large bowel, a clinical review. (dissertation), Dhaka: BCPS1976.

25. Siddique AKMZ. Colorectal cancer, a clinical pathological study (dissertation) Dhaka: BCPS1985.

26. Floyd CE, Cohn IJr. Obstruction in cancer of the colon. Ann surg 1967 May; 165(5):721-31. 